\title{
A comunicação em projetos de TI: uma análise comparativa das equipes de sistemas e de negócios
}

\author{
Marly Monteiro de Carvalho \\ Daniela Mirandola \\ POLI-USP
}

\begin{abstract}
Resumo
Este artigo tem por objetivo compreender o processo de comunicação em projetos de Tecnologia da Informação (TIJ. Além disso, este estudo busca investigar a influência do perfil profissional, considerando-se as áreas de sistemas e de negócios, na importância atribuída à área de comunicações em projetos. A abordagem metodológica selecionada usa uma combinação de métodos qualitativos e quantitativos. Um estudo de caso foi desenvolvido em uma empresa prestadora de serviços de TI de grande porte. Adicionalmente, foram coletadas informações através de um questionário do tipo survey preenchido por 57 profissionais da empresa estudada, envolvidos em projetos de TI, dos quais 58\% são da área de sistemas e 42\% da área de negócios. Os resultados sugerem que existem características distintivas entre estes dois perfis de profissional.
\end{abstract}

Palavras-chave

Gestão de projetos; comunicação em projetos; projetos de tecnologia da informação.

\section{Communication in IT projects: a comparative analysis between information systems and business teams}

\begin{abstract}
This paper aims to understand the communications process in Information Technology (IT) projects. Furthermore, this study investigated the influence of professional profile on the perception of project communication importance, considering both systems and business-oriented areas. The selected methodological approach uses a combination of qualitative and quantitative methods. A case study was performed in large IT Service Company. Besides, data were gathered from a questionnaire survey of 57 professionals of the studied company involved in IT projects, which 58\% represented the system-oriented area and $42 \%$ the business-oriented area. The results suggested that there are distinctive characteristics between these two professionals' profiles.
\end{abstract}

Key words

Project management, project communication, information technology projects. 


\section{INTRODUĈ̣̃O}

Tornar as informações disponíveis e inteligíveis é uma arte, a arte de tornar comum, comunicar-se. Assim como em nosso cotidiano, nas organizações e, em especial, na área de gerenciamento de projetos, alguns autores sustentam que o processo de comunicação está significativamente associado ao sucesso ou fracasso na atividade de projetos (PINTO; SLEVIN, 1988; PINTO; PRESCOTT, 1988; PINTO; MANTEL, 1990; BELOUT; GAUVREAU, 2004).

Uma referência bastante difundida na área de gerenciamento de projetos é o guia de Conhecimentos em Gestão de Projetos (Project Management Body of Knowledge - PMBoK), elaborado pelo Project Management Institute (PMI), que destaca um capítulo para a área de comunicação, o que reforça sua importância no contexto de projetos (PMI, 2004).

Carvalho et al. (2003) sustentam que em projetos de TI o emprego de técnicas de gerenciamento de projetos tem se intensificado, tanto no âmbito dos projetos (PMBoK), como de modelos de maturidade organizacionais tais como o Capability Maturity Model (CMM) (HUMPHREY, 1989) e o Organizational Project Management Maturity Model (OPM3) (PMI, 2003).

Por outro lado, em projetos de TI é marcante a interação entre os profissionais de diferentes áreas, o que pode gerar lacunas nos processos de comunicação. Kirsc et al. (2002) alertam que de modo crescente os "clientes de negócios" estão ativamente liderando projetos de Tecnologia de Informação (TI), o que pode se configurar em fontes de conflito e barreiras à comunicação

Este artigo visa compreender o processo de comunicação em projetos de Tecnologia da Informação (TI), bem como verificar se existem diferenças na percepção dos profissionais da área de negócios e de desenvolvimento de sistemas, no que concerne à importância da área de comunicações no gerenciamento dos projetos.

A abordagem metodológica adotada foi a de estudo de caso, cuja unidade de análise corresponde a uma empresa prestadora de serviços de TI de grande porte, com utilização de ferramentas qualitativas e quantitativas de análise.

$\mathrm{O}$ artigo está estruturado em cinco seções. A próxima seção apresenta a síntese da discussão teórica sobre o processo de comunicação em projetos. Em seguida, apresenta-se a abordagem metodológica utilizada na pesquisa. A seção Resultados da pesquisa apresenta e analisa os resultados obtidos. Finalmente, a última seção traz as conclusões e limitações do estudo.

\section{O PROCESSO DE COMUNICAC̣ÃO}

Como observa Muchielli (1993), a comunicação está presente na literatura organizacional com a mesma importância que a gestão da produção, a gestão financeira ou a gestão de recursos humanos, etc. Para Arantes (1998), a comunicação é a base para a sobrevivência, o crescimento e a continuidade das organizações. Somente por meio de processo de comunicação eficaz é possível que as atividades distribuídas entre os vários colaboradores que integram uma organização atinjam os objetivos planejados.

De maneira geral, Ferreira (1996) identifica no processo de comunicação os seguintes elementos básicos: emissor; receptor; mensagem; canal; codificação / decodificação; feedback. Comunicação, segundo o dicionário Aurélio (FERREIRA, 1988) pode ser entendida como "ato ou efeito de emitir, transmitir e receber mensagens por meio de métodos e/ou processos convencionais, quer através da linguagem falada ou escrita, quer de outros sinais, signos ou símbolos, quer aparelhamento técnico especializado, sonoro e/ou visual".

No processo de comunicação, o emissor é responsável por tornar as informações claras, coerentes e completas, o que permite que o receptor a receba e compreenda. O receptor, por sua vez, é responsável por garantir que a informação foi recebida de forma integral e entendida corretamente (PMI, 2004). Infelizmente, isto nem sempre acontece, pois embora o conceito de comunicação seja simples de entender, na prática é um processo complexo. A ausência de efetividade no processo comunicativo pode ser decorrente do surgimento de barreiras à comunicação no dia a dia das organizações, conforme será discutido na próxima seção.

\section{Entendendo as barreiras à comunicação}

Diversos são os autores que abordam as barreiras que interferem no processo de comunicação. De acordo com Ferreira (1996), as barreiras à comunicação podem ser tanto físicas como de significado ou psicológicas. As barreiras físicas são obstáculos ao longo da transmissão da informação. Já as chamadas barreiras de significado ou barreiras psicológicas são relacionadas às variáveis interpessoais entre emissor / receptor e à utilização de códigos não partilhados.

As barreiras físicas podem estar associadas aos meios de comunicação utilizados, portanto, alguns autores destacam que a seleção do meio de comunicação deve ser feita considerando-se os seguintes aspectos: velocidade necessária para distribuição das informações, tecnologia disponível, níveis de segurança (senhas, clausulas de privacidade, etc), duração do projeto/ tamanho e outras características do projeto que dimensionem o porte do projeto (CARVALHO; RABECHINI JR., 2005 e 2006; FOX, 2001).

Outra classificação mais estratificada é apresentada por Fox (2001), que desdobra as barreiras à comunicação em quatro grandes grupos, quais sejam: ambiente, verbal, interpessoal e reações emocionais. Para cada grupo o autor exemplifica as possíveis barreiras: 
- Ambiente: desconforto físico, distrações visuais, interrupções, barulho, etc.

- Verbal: pessoas que falam rápido demais ou não explicam o que estão transmitindo; uso de gírias, jargões ou acrônimos; não saber ouvir, não prestar atenção, etc.

- Interpessoal: suposições incorretas e diferentes percepções, diferenças de linguagem, desconfiança, diferenças de status, diferenças étnicas, etc.

- Reações Emocionais: raiva, amor, autodefesa, ódio, medo, vergonha.

Segundo Penteado (1980), barreiras à comunicação podem ser facilmente detectadas no ambiente organizacional, destacando-se problemas de centralização de informações e questões que envolvem interpretações dúbias. Este autor adverte ainda que as competências comunicacionais, que consistem na capacidade de um grupo de codificar, transmitir e decodificar informações, são requisitos necessários mas não suficientes para a eficácia no processo de comunicação. É preciso que emissor e receptor estejam imbuídos por um sentido compartilhado. $\mathrm{O}$ autor conclui que as organizações precisam desenvolver competência estratégica para uma comunicação eficaz, que amplie a capacidade de um grupo de interpretar as informações e criar significados compartilhados. estar presentes se quisermos construir uma base sólida para a comunicação. $\mathrm{O}$ autor define:

Estimular $=$ fortalecer, encorajar, dar poder - estimular o outro a expressar suas idéias.

> Estimar = valorizar, respeitar, considerar, compreender, apreciar - efetivamente, ouvir o que o outro diz.

Para criar um ambiente de confiança, Fox (2001) destaca a importância de cinco ações que permitem envolver as pessoas e garantir um entendimento comum de idéias, ações e resultados, quais sejam: (1) compartilhar pensamentos e sentimentos; (2) assumir compromissos que se possam cumprir; (3) admitir erros; (4) requisitar e aceitar feedback, (5) reconhecer e testar suposições. O uso sistemático destas técnicas na organização encoraja sua disseminação entre os colaboradores.

No contexto específico de projetos de TI merecem destaque neste artigo as barreiras de comunicação que podem surgir na interação dos profissionais da área de negócio, em geral responsáveis pela interface com o cliente/usuário, e o pessoal de desenvolvimento de sistemas. Kirsc et al. (2002) alertam que de modo crescente os "clientes de negócios" estão ativamente liderando projetos de tecnologia de informação (TI), freqüentemente em colaboração com profissionais de sistemas, exercendo um maior grau de controle sobre os projetos. Por controle os autores definem "todas as tentativas para motivar os indivíduos a alcançarem objetivos desejados, que pode ser exercido via modos formais e informais." (KIRSC et al , 2002: p.484). Os resultados empíricos obtidos pelos autores destacam o papelchave que o conhecimento representa na escolha do modo de controle e reconhecem a importância de se construir e manter associações verdadeiras através das relações

As barreiras à comunicação dependem, portanto, do individual e do coletivo. Alguns fatores que podem afetar o significado no processo de comunicação são: a relação funcional entre emissor e receptor; ambiente cultural e educação; as experiências vividas individualmente; as emoções e a semântica (PENTEADO,1980).

Fox (2001) acrescenta que um ambiente de confiança é essencial à comunicação. Quando ocorre falta de confiança, as pessoas concentram-se mais nas suas suposições e temores, o que gera ruído. Em contrapartida, quando a confiança existe, as pessoas pedem ajuda, falam aberta e honestamente, assumem riscos, aceitam novos desafios e desenvolvem suas atividades com menos ansiedade e estresse. Para o autor, um ambiente de confiança está embasado em pelo menos dois princípios fundamentais, estímulo e estima, que devem dos clientes de negócios e do pessoal de processo de TI.

\section{A comunicação em projetos}

No guia PMBoK, a definição de projeto é "um empreendimento temporário feito para criar um produto, serviço ou resultado único" (PMI, 2004). Já Ruuska e Vartiainen (2003) definem um projeto como um sistema de trabalho complexo no qual elementos humanos, organizacionais, procedurais e técnicos estão integrados. Portanto, se um projeto envolve interação humana, isto requer comunicação.

Rockart (1979), introduziu o conceito de FCSs em seu artigo "Chief executives define their own data needs", definindo-o como: "um limitado número de áreas nas quais os resultados, se satisfatórios, irão assegurar um desempenho competitivo de sucesso para a organização. São as 
poucas áreas-chave em que as "coisas devem dar certo" para que o negócio floresça." (ROCKART, 1979, p.85). O autor alerta ainda que estas áreas-chave demandam cuidado constante da administração.

As áreas consideradas fatores críticos de sucesso (FCSs) no gerenciamento de projetos por diversos autores são: prazo, custo, escopo e qualidade (GRANOT, 1997; DINSMORE, 1998; PMI, 2004). Pinto e Sleven (1987) acrescentam ainda que um projeto é considerado um sucesso em sua implementação caso atenda a quatro critérios: tempo, custo, eficácia e satisfação do cliente.

Aárea de Comunicações é destacada por Ruuska e Vartiainen (2003), que argumentam que a comunicação entre os stakeholders de um projeto é um FCS. Corrobora esta visão Obikunle (2001), ressaltando que "a comunicação é a alma do gerenciamento de projetos" e que "o vácuo criado pela falha de comunicação rapidamente será preenchido por rumores e interpretações errôneas". No contexto brasileiro, um estudo empírico desenvolvido por Rabechini Jr. et al., (2002) com gerentes de projeto também identificou a área de comunicação como um dos fatores críticos de sucesso em projetos.

No PMBoK, a área de comunicação configura entre as nove áreas de conhecimento da Gerência de Projetos. Conforme esse guia, a comunicação é um tema abrangente e requer um corpo de conhecimento que extrapola o contexto do projeto. A Gerência das Comunicações do Projeto envolve a aplicação específica destes conceitos e conhecimentos às necessidades específicas do projeto (PMI, 2004).

A Gerência das Comunicações do Projeto compreende quatro processos para assegurar que a geração, coleta, distribuição, armazenamento e apresentação das informações do projeto sejam realizados adequadamente e no tempo certo. Esta área é composta dos seguintes processos (PMI, 2004):

1. Planejamento das Comunicações: identifica as informações que os interessados precisam ao longo do projeto: quem são eles, quais os níveis de interesse no projeto, quais necessidades de informação.

2. Distribuição de informações: disponibiliza as informações aos interessados.

3. Relato de Desempenho: coleta e dissemina informações do desempenho de projeto.

4. Gestão dos interessados (stakeholders): administra a comunicação que visa satisfazer as necessidades dos interessados.

É importante destacar que a terceira edição deste guia (PMI, 2004) apresenta algumas alterações nestes processos com relação à segunda edição (PMI, 2000). O processo de encerramento administrativo foi retirado da área de Gestão das Comunicações e transferido para a área de Gestão da Integração, e um novo processo - gerenciamento dos interessados (stakeholders) - foi introduzido. Esta alteração supre uma carência que as edições anteriores apresentavam, no que concerne ao envolvimento explícito dos stakeholders nos processos de Gestão de Projetos (CARVALHO; RABECHINI JR., 2005). As principais saídas dos processos de gerenciamento das comunicações são o Plano de Gerenciamento das Comunicações e os Relatórios de Desempenho.

\section{\ s organizações precisam desenvolver mpetência estratégica para uma icação eficaz, que amplie a capacidade de um grupo de interpretar as informações e criar significados compartilhados.}

\section{METODOLOGIA DE PESQUISA}

O objetivo do artigo consiste em estudar o processo de comunicação em projetos de Tecnologia da Informação (TI), bem como verificar se existem diferenças na percepção dos profissionais da área de negócios e de desenvolvimento de sistemas, no que concerne à importância da área de comunicações no gerenciamento dos projetos. Com base no quadro teórico delineado nas seções anteriores, foram levantadas algumas questões de pesquisa:

- Qual a importância da comunicação quando comparada com as outras áreas de conhecimento em gerenciamento de projetos?

- Como se dá o processo de comunicação em projetos TI em uma empresa?

- Quais seriam as maiores barreiras à comunicação percebidas pelas pessoas de áreas técnicas e pelas pessoas da área de negócios e relacionamento com clientes?

Além disto, o presente trabalho pretende investigar a hipótese de diferenças na percepção da importância da área de comunicações entre os profissionais de negócios e de sistemas, no contexto de projetos de TI.

A abordagem metodológica adotada foi a de estudo de caso. Os critérios de seleção do caso foram: o porte da empresa; complexidade dos projetos de TI e a interação de profissionais de diferentes áreas. A escolha destes critérios justifica-se, pois buscava-se estudar a Gestão das Comunicações em um ambiente de projetos em que procedimentos e 
processos fossem necessários, o que com poucos envolvidos nem sempre ocorre.

Com base nos critérios apresentados, selecionou-se uma empresa prestadora de serviços de informações comerciais de grande porte, com foco no processamento de cartão de crédito. Foi utilizado o tipo de entrevista denominado levantamento, que é composta por questões mais estruturadas (YIN, 1991). O questionário era composto de seis blocos: caracterização do entrevistado, importância da área de comunicações, planejamento das comunicações do projeto, distribuição das informações, relatórios de desempenho dos projetos e barreiras de comunicação. As questões abordavam aspectos relacionados às boas práticas de gestão das comunicações em projetos, as principais barreiras à comunicação e aos fatores críticos de sucesso em projetos. O questionário continha 16 questões de múltipla escolha e 2 questões abertas.

\section{s três áreas com percepção de - importância alta pelo maior número de respondentes foram Escopo (60\%), Qualidade (44\%) e Comunicação (42\%).}

Em seguida serão apresentados os resultados obtidos nos seis blocos do questionário.

\section{Caracterização da amostra}

Os funcionários que fizeram parte da amostra pertencem às áreas de sistemas e de negócios, selecionados a partir de um conjunto de projetos de impacto desenvolvidos na organização nos últimos anos.

Os respondentes são na sua maioria homens (67\%), com até 30 anos de idade (43\%), sendo que apenas 12\% destes funcionários têm mais que 40 anos.

Em termos da função que os entrevistados desempenhavam na organização, $18 \%$ eram gerentes, $21 \%$ analistas e $61 \%$ consultores. Já os dados referentes à experiência destes funcionários revelaram que $28 \%$ da amostra pode ser considerada sênior na atividade de projetos, com mais de 10 anos de experiência, sendo que uma parcela similar (30\%) é de funcionários pouco experientes, com até 3 anos de participação em projetos. No que concerne ao tempo de trabalho na empresa, a maior parcela (62\%) tem até 3 anos de casa, dos quais $38 \%$ têm menos que 1 ano. Somente $5 \%$ da amostra estão na empresa há mais de 10 anos.
Os questionários foram distribuídos aos gerentes, consultores e analistas envolvidos com os projetos de TI, tanto nas áreas de sistemas quanto nas áreas de negócios da empresa selecionada, com o intuito de perceber características distintivas entre estes dois perfis de profissionais. Foram distribuídos ao todo 76 questionários com um retorno de 57 questionários (75\% respostas válidas). Dos questionários respondidos, $58 \%$ foram respondidos por profissionais da área de sistemas e $42 \%$ da área de negócios.

A próxima seção apresenta os principais resultados da pesquisa.

\section{RESULTADOS DA PESQUISA}

Esta organização conta com cerca 3.000 funcionários e um faturamento anual na ordem de R $\$ 750$ milhões. A organização analisada realiza, em sua grande maioria, projetos complexos e de grade porte.

Sua estrutura organizacional é predominantemente funcional, com áreas e gestores bem definidos. Entretanto, no que se refere à gestão de projetos, pode ser considerada como uma estrutura matricial fraca, em que os colaboradores, considerados como "Gerentes de Projetos", apesar de serem hierarquicamente consultores e analistas, têm o domínio do projeto, mas se reportam a um gerente de área, sendo caracterizado como um "facilitador" do relacionamento nos projetos entre áreas.

\section{Importância da comunicação em projetos}

O objetivo deste bloco do questionário era responder a hipótese de diferenças na percepção da importância da área de comunicações entre os profissionais de negócios e de sistemas, no contexto de projetos de TI. Para este fim foram elaboradas duas perguntas.

A primeira pergunta questionava a importância da comunicação, atribuindo uma classificação em cinco níveis de importância, conforme resultados da Tabela 1 .

Analisando a Tabela 1, percebe-se que, de uma forma geral, os respondentes consideraram a importância da comunicação em projetos altíssima. Para validar a hipótese foi feito o teste de independência, Qui-quadrado, das variáveis "importância da comunicação em projetos" e "áreas de atuação do entrevistado-sistemas e negócios", utilizandose o software estatístico Minitab. A hipótese foi testada da seguinte forma:

Ho: A área funcional (sistema ou negócios) não exerce efeito na percepção de importância da área de comunicações em gestão de projetos

H1: A área funcional (sistema ou negócios) exerce efeito na percepção de importância da área de comunicações em gestão de projetos

Os resultados obtidos apontam que não há evidências para rejeitar Ho $(C h i-S q=0,708 ; D F=2 ; P$-Value $=0,702)$, 
ou seja, não se pode afirmar que existam diferenças significativas de percepção da importância da comunicação em projetos entre os profissionais de negócios e de sistemas.

A fim de validar a informação sobre a importância da comunicação em projetos, o questionário dispunha de uma segunda questão, que procurava comparar a Comunicação com as demais áreas de Gestão de Projetos, conforme o guia PMBoK (ver Tabelas 2). A questão apresentava as nove áreas de conhecimento, distribuídas no instrumento de pesquisa de forma aleatória, com três níveis de importânciaalta, média e baixa.

Em uma primeira análise à Tabela 2, pode-se observar em destaque as áreas que obtiveram mais de $50 \%$ de percepção de importância, considerando sistemas, negócios e o geral, com todos os respondentes. $\mathrm{Na}$ área de sistemas verificouse que é dada alta importância às áreas de Escopo (64\%), Qualidade (55\%) e Comunicação (55\%). As áreas de prazos e custos, consideradas por diversos autores como fatores críticos de sucesso em projetos, aparecem com um grau de importância alto para apenas $30 \%$ e $24 \%$ dos respondentes de sistemas, respectivamente.
$\mathrm{Na}$ área de Negócios, como se pode observar na Tabela 2, apenas na área de gestão de Escopo (54\%) a percepção predominante dos respondentes foi de importância alta, seguida da Gestão de Suprimentos (46\%) e Gestão da Integração (42\%). Cabe notar que, para a área de Negócios, a área de Suprimentos está entre as mais importantes, para Sistemas esta área foi considerada a menos importante (mais da metade dos respondentes considera a importância baixa - 55\%).

A área de Suprimentos, para os profissionais da área de negócios da empresa analisada, significa ter os serviços disponíveis e com qualidade, sobretudo os relacionados às Centrais de Atendimento a Cliente, Processamento de Informações e envio de impressos, incluindo faturas e os plásticos de cartão de crédito. Isto porque, boa parte desses serviços é realizada por parceiros contratados e a responsabilidade sobre este item é das equipes de Negócios.

Analisando os dados agregados, com o geral da amostra, as três áreas com percepção de importância alta pelo maior número de respondentes foram Escopo (60\%), Qualidade (44\%) e Comunicação (42\%), como mostra a Figura 1. Curiosamente, os outros dois fatores críticos de sucesso em projetos - prazo e custo - mantêm-se nos últimos lugares na

Tabela 1: Importância da comunicação em projetos.

\begin{tabular}{|c|c|c|c|c|c|c|}
\hline \multirow{2}{*}{$\frac{\text { GRAU DE IMPORTÂNCIA }}{\text { Nenhuma }}$} & \multicolumn{2}{|c|}{ SISTEMAS } & \multicolumn{2}{|c|}{ NEGócIOS } & \multicolumn{2}{|c|}{ GERAL } \\
\hline & 0 & $0 \%$ & 0 & $0 \%$ & 0 & $0 \%$ \\
\hline Baixa & 0 & $0 \%$ & 0 & ०\% & 0 & $0 \%$ \\
\hline Média & 3 & $9 \%$ & 1 & $4 \%$ & 4 & $7 \%$ \\
\hline Alta & 10 & $30 \%$ & 9 & $38 \%$ & 19 & $33 \%$ \\
\hline Altíssima & 20 & $61 \%$ & 14 & $58 \%$ & 34 & $60 \%$ \\
\hline Total & 33 & $100 \%$ & 24 & $100 \%$ & 57 & $100 \%$ \\
\hline
\end{tabular}

Tabela 2: Classificação de grau de importância entre as áreas do PMBoK.

\begin{tabular}{|c|c|c|c|c|c|c|c|c|c|c|c|c|c|c|c|c|c|c|}
\hline \multirow{3}{*}{$\begin{array}{l}\text { ÁREAS DO PMBoK } \\
\text { Comunicação }\end{array}$} & \multicolumn{6}{|c|}{ SISTEMAS } & \multicolumn{6}{|c|}{ NEGÓCIOS } & \multicolumn{6}{|c|}{ GERAL } \\
\hline & \multicolumn{2}{|c|}{ BAIXA } & \multicolumn{2}{|c|}{ MÉDIA } & \multicolumn{2}{|c|}{ ALTA } & \multicolumn{2}{|c|}{ BAIXA } & \multicolumn{2}{|c|}{ MÉDIA } & \multicolumn{2}{|c|}{ ALTA } & \multicolumn{2}{|c|}{ BAIXA } & \multicolumn{2}{|c|}{ MÉDIA } & \multicolumn{2}{|c|}{ ALTA } \\
\hline & 4 & $12 \%$ & 11 & $33 \%$ & 18 & $55 \%$ & 9 & $38 \%$ & 9 & $38 \%$ & 6 & $25 \%$ & 13 & $23 \%$ & 20 & $35 \%$ & 24 & $42 \%$ \\
\hline Prazo & 15 & $45 \%$ & 8 & $24 \%$ & 10 & $30 \%$ & 8 & $33 \%$ & 10 & $42 \%$ & 6 & $25 \%$ & 23 & $40 \%$ & 18 & $32 \%$ & 16 & $28 \%$ \\
\hline Escopo & 6 & $18 \%$ & 6 & $18 \%$ & 21 & $64 \%$ & 10 & $42 \%$ & 1 & $4 \%$ & 13 & $54 \%$ & 16 & $28 \%$ & 7 & $12 \%$ & 34 & $60 \%$ \\
\hline Custo & 13 & $39 \%$ & 12 & $36 \%$ & 8 & $24 \%$ & 6 & $25 \%$ & 10 & $42 \%$ & 8 & $33 \%$ & 19 & $33 \%$ & 22 & $39 \%$ & 16 & $28 \%$ \\
\hline Qualidade & 2 & $6 \%$ & 13 & $39 \%$ & 18 & $55 \%$ & 5 & $21 \%$ & 12 & $50 \%$ & 7 & $29 \%$ & 7 & $12 \%$ & 25 & $44 \%$ & 25 & $44 \%$ \\
\hline Risco & 8 & $24 \%$ & 15 & $45 \%$ & 10 & $30 \%$ & 2 & $8 \%$ & 14 & $58 \%$ & 8 & $33 \%$ & 10 & $18 \%$ & 29 & $51 \%$ & 18 & $32 \%$ \\
\hline Suprimentos & 18 & $55 \%$ & 5 & $15 \%$ & 10 & $30 \%$ & 10 & $42 \%$ & 3 & $13 \%$ & 11 & $46 \%$ & 28 & $49 \%$ & 8 & $14 \%$ & 21 & $37 \%$ \\
\hline Recursos Humanos & 9 & $27 \%$ & 12 & $36 \%$ & 12 & $36 \%$ & 8 & $33 \%$ & 8 & $33 \%$ & 8 & $33 \%$ & 17 & $30 \%$ & 20 & $35 \%$ & 20 & $35 \%$ \\
\hline Integração & 10 & $30 \%$ & 10 & $30 \%$ & 13 & $39 \%$ & 11 & $46 \%$ & 3 & $13 \%$ & 10 & $42 \%$ & 21 & $37 \%$ & 13 & $23 \%$ & 23 & $40 \%$ \\
\hline
\end{tabular}


percepção geral, considerando-se todos os respondentes, conforme se pode observar na Tabela 2 .

Finalmente, é importante observar que, embora na Tabela 1 a importância da área de Comunicações tenha sido julgada altíssima, quando analisada isoladamente, na análise comparativa com as demais áreas do PMBoK este resultado não se mantém para a área de Negócios. Em contraposição a Sistemas, verificou-se que Comunicação está em último lugar na classificação da área de Negócios, com apenas 25\% (ver Tabela 3). A Figura 2 apresenta a análise comparativa para os dois setores no que concerne à importância da área de Comunicações.
Para encerrar esta análise, foi feito um novo teste de independência, Qui-quadrado, das variáveis "importância da comunicação em projetos" e "áreas de atuação do entrevistado - sistemas e negócios", considerando-se os resultados obtidos na segundo pergunta, utilizando-se o software estatístico Minitab. A hipótese foi testada da seguinte foram:

Ho: A área funcional (sistema ou negócios) não exerce efeito na percepção de importância da área de comunicações em gestão de projetos, quando comparada às demais áreas de conhecimento

Figura 1: Fatores críticos de sucesso.

Fatores Críticos de Sucesso

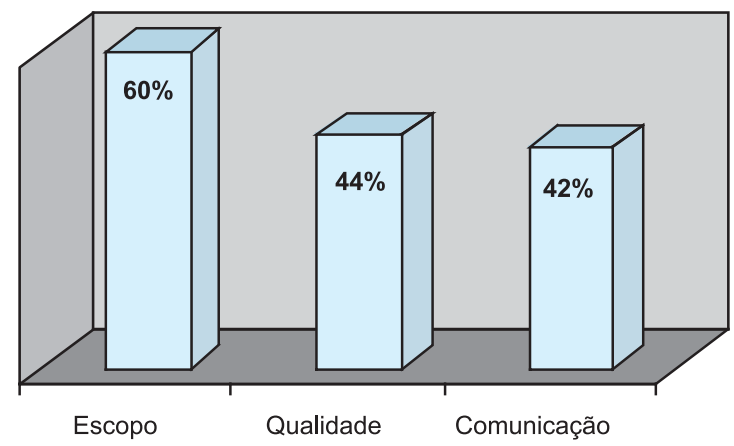

Figura 2: Análise comparativa da importância da comunicação — sistemas x negócios.
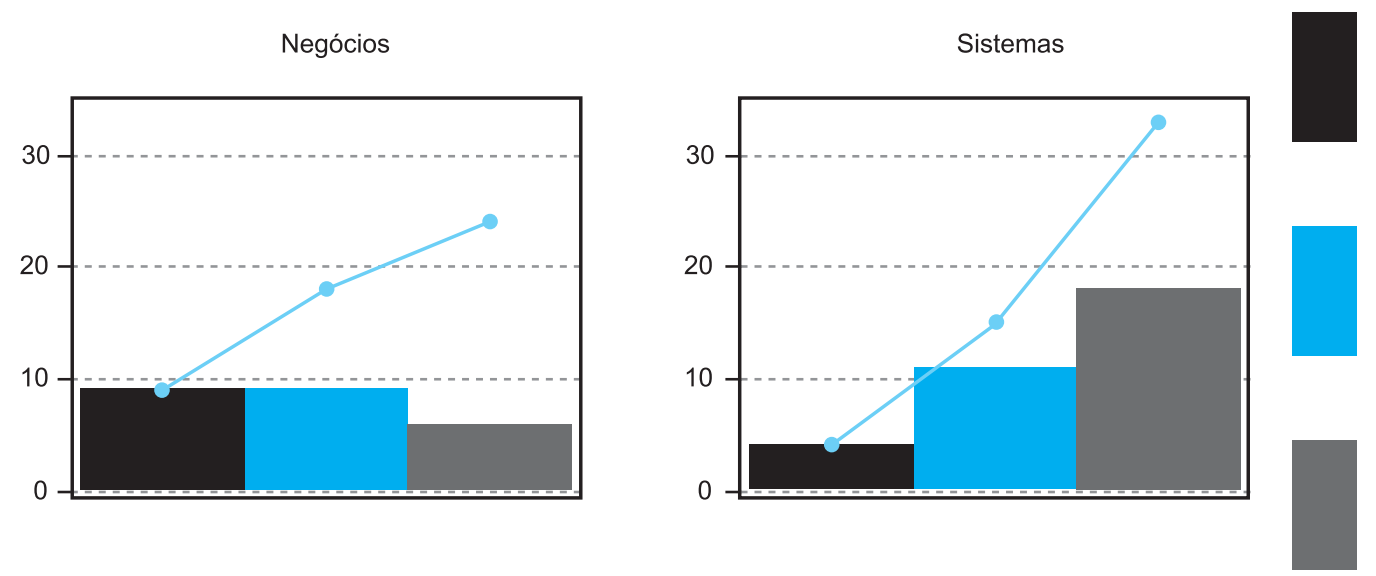
H1: A área funcional (sistema ou negócios) exerce efeito na percepção de importância da área de comunicações em gestão de projetos, quando comparada às demais áreas de conhecimento

Os resultados obtidos apontam que há evidências para rejeitar Ho $(\mathrm{Chi}-\mathrm{Sq}=6,873 ; \mathrm{DF}=2$; P-Value $=0,032)$, ou seja, pode-se afirmar que existem diferenças significativas de percepção da importância da comunicação em projetos entre os profissionais de negócios e de sistemas.

Este resultado é um indício interessante. Apesar de ambos os profissionais valorizarem a área de comunicações de maneira geral, quando é feita a análise comparativa entre as áreas de conhecimento em Gestão de Projeto, apenas os profissionais da área de sistemas mantêm a percepção de alta importância.

\section{Processo de comunicação em projetos de TI}

Este bloco do questionário visava responder a questão de pesquisa "Como se dá o processo de comunicação em projetos TI em uma empresa?" apresentada na seção de metodologia deste artigo. No instrumento de pesquisa havia questões relacionadas às principais saídas deste processo: o plano de comunicações em projetos e os relatórios de desempenho. Além disto, havia questões relativas à distribuição das informações.

\section{Planejamento da comunicação em projetos}

Para estudar o processo de planejamento da comunicação em projetos na percepção dos participantes da pesquisa foram feitas duas perguntas. A primeira pergunta tinha por objetivo identificar qual a porcentagem dos projetos desenvolvidos pelo respondente que tinham Plano Formal de Comunicação, para tal, o entrevistado escolhia entre 5 níveis, conforme apresentado na Tabela 3.

Pode-se observar na Tabela 3 que apenas 3 respondentes (5\%) fizeram o Plano Formal de Comunicações em todos os projetos que participaram, sendo 2 da área de negócios e 1 da área de sistemas. A maioria dos respondentes $(56 \%$ do geral) fez o referido plano em até $40 \%$ dos projetos em que participou. Segundo alguns relatos obtidos nas questões abertas, só os projetos mais complexos dispunham deste tipo de plano.

A segunda pergunta buscava compreender se a existência do Plano Formal de Comunicações contribuía para o processo de comunicação, para tal, o entrevistado escolhia entre 3 níveis, conforme apresentado na Tabela 4.

Observa-se que, embora o plano de comunicações não

Tabela 3: Percentual de projetos com plano de comunicação.

\begin{tabular}{|c|c|c|c|c|c|c|}
\hline \% PROJETOS & \multicolumn{2}{|c|}{ SISTEMAS } & \multicolumn{3}{c|}{ GEGAL } \\
\hline $0 \%$ & 2 & $6 \%$ & 1 & $4 \%$ & 3 & $5 \%$ \\
\hline $20 \%$ & 7 & $21 \%$ & 3 & $13 \%$ & 10 & $18 \%$ \\
\hline $40 \%$ & 8 & $24 \%$ & 11 & $46 \%$ & 19 & $33 \%$ \\
\hline $60 \%$ & 5 & $15 \%$ & 6 & $25 \%$ & 11 & $19 \%$ \\
\hline $80 \%$ & 10 & $30 \%$ & 1 & $4 \%$ & 11 & $19 \%$ \\
\hline $100 \%$ & 1 & $3 \%$ & 2 & $8 \%$ & 3 & $5 \%$ \\
\hline
\end{tabular}

Tabela 4: Contribuição do plano de comunicação.

\begin{tabular}{|c|c|c|c|c|c|c|}
\hline \multirow[b]{2}{*}{ Facilitava } & \multicolumn{2}{|c|}{ SISTEMAS } & \multicolumn{2}{|c|}{ NEGócIOS } & \multicolumn{2}{|c|}{ GERAL } \\
\hline & 29 & $88 \%$ & 22 & $96 \%$ & 51 & $91 \%$ \\
\hline Pouco contribuía & 3 & $9 \%$ & 1 & $4 \%$ & 4 & $7 \%$ \\
\hline \multirow[t]{2}{*}{ Em nada contribuía } & 1 & $3 \%$ & 0 & $0 \%$ & 1 & $2 \%$ \\
\hline & 33 & $100 \%$ & 23 & $100 \%$ & 56 & $100 \%$ \\
\hline
\end{tabular}


seja uma prática freqüente nos projetos desenvolvidos na empresa estudada, os respondentes são praticamente unânimes (91\% no geral) em afirmar que sua existência facilitava o processo de comunicação.

\section{- mbora a importância da área de Comunicações tenha sido julgada} altíssima, quando analisada isoladamente, na análise comparativa com as demais áreas do PMBoK este resultado não se mantém para a área de Negócios.

\section{Distribuição das informações}

$\mathrm{O}$ instrumento de pesquisa continha uma pergunta sobre o processo de distribuição de informações, sobretudo quanto aos meios de comunicação utilizados, que foram apresentados em uma lista fechada, na qual o respondente podia arbitrar mais do que uma opção. A Tabela 5 e a Figura 3 apresentam os resultados obtidos, estratificados por áreas: Sistemas e Negócios.

A lista apresentada não foi exaustiva, pois poderiam constar outros itens como: chat; mensageiros instantâneos; site do projeto; sistemas de gestão de documentos, entre outros. No entanto, havia um campo aberto denominado outros, mas que não foi preenchido por nenhum dos respondentes.
Os quatros meios de comunicação mais utilizados em ambas as áreas são: reuniões (20\% geral), e-mail (20\% geral), documentos formais ( $17 \%$ geral) e telefone ( $15 \%$ geral).

Segundo relatos dos respondentes, com a correria e turbulências do dia-a-dia, faz-se necessária a utilização de ferramentas que facilitem e agilizem a transmissão de informações, por isso o uso intenso de e-mail e telefone. Entretanto, vários entrevistados relataram a importância das reuniões, pois julgam o contato pessoal bastante decisivo para uma comunicação eficaz nos projetos.

\section{Relatórios de desempenho}

$\mathrm{O}$ instrumento de pesquisa dispunha de duas perguntas relativas aos relatórios de desempenho. A primeira perguntava se havia relatório de desempenho nos projetos em que os pesquisados participaram, havendo cinco níveis de respostas possíveis, conforme ilustra a Tabela 6 .

Pode-se observar na Tabela 6 que para a maioria dos entrevistados (51\% geral) a elaboração de relatórios de desempenho não é uma prática freqüente na organização estudada (37\% praticamente não e $14 \%$ não).

A segunda pergunta versava sobre a discussão dos resultados de desempenho do projeto, também com cinco níveis de respostas possíveis, mas neste caso o entrevistado podia opinar por mais um nível, como mostra a Tabela 7.

Observa-se que $30 \%$ das respostas julgaram que as reuniões eram esporádicas e não suficientes, mas a proporção desta resposta entre os profissionais de sistemas (37\%) é maior que dos profissionais de negócios (23\%). Por outro

Tabela 5: Meios de comunicação.

\begin{tabular}{|c|c|c|c|c|c|c|}
\hline MEIOS DE COMUNICAÇÃO & \multicolumn{2}{|c|}{ SISTEMAS } & \multicolumn{2}{|c|}{ NEGÓCIOS } & \multicolumn{2}{|c|}{ GERAL } \\
\hline Reuniões & 33 & $20 \%$ & 22 & $20 \%$ & 55 & $20 \%$ \\
\hline Documentos Formais & 29 & $18 \%$ & 16 & $15 \%$ & 45 & $17 \%$ \\
\hline Conversas Informais & 16 & $10 \%$ & 11 & $10 \%$ & 27 & $10 \%$ \\
\hline E-Mail & 31 & $19 \%$ & 23 & $21 \%$ & 54 & $20 \%$ \\
\hline Software de GP & 15 & $9 \%$ & 11 & $10 \%$ & 26 & $10 \%$ \\
\hline Banco de Dados do Projeto & 8 & $5 \%$ & 6 & $5 \%$ & 14 & $5 \%$ \\
\hline Telefone & 23 & $14 \%$ & 18 & $16 \%$ & 41 & $15 \%$ \\
\hline Fax & 1 & $1 \%$ & 0 & $0 \%$ & 1 & ०\% \\
\hline Videoconferências & 2 & $1 \%$ & 0 & $0 \%$ & 2 & $1 \%$ \\
\hline \multirow[t]{2}{*}{ Intranet do Projeto } & 4 & $2 \%$ & 3 & $3 \%$ & 7 & $3 \%$ \\
\hline & 162 & $100 \%$ & 110 & $100 \%$ & 272 & $100 \%$ \\
\hline
\end{tabular}


Figura 3: Meios de comunicação utilizados - geral.

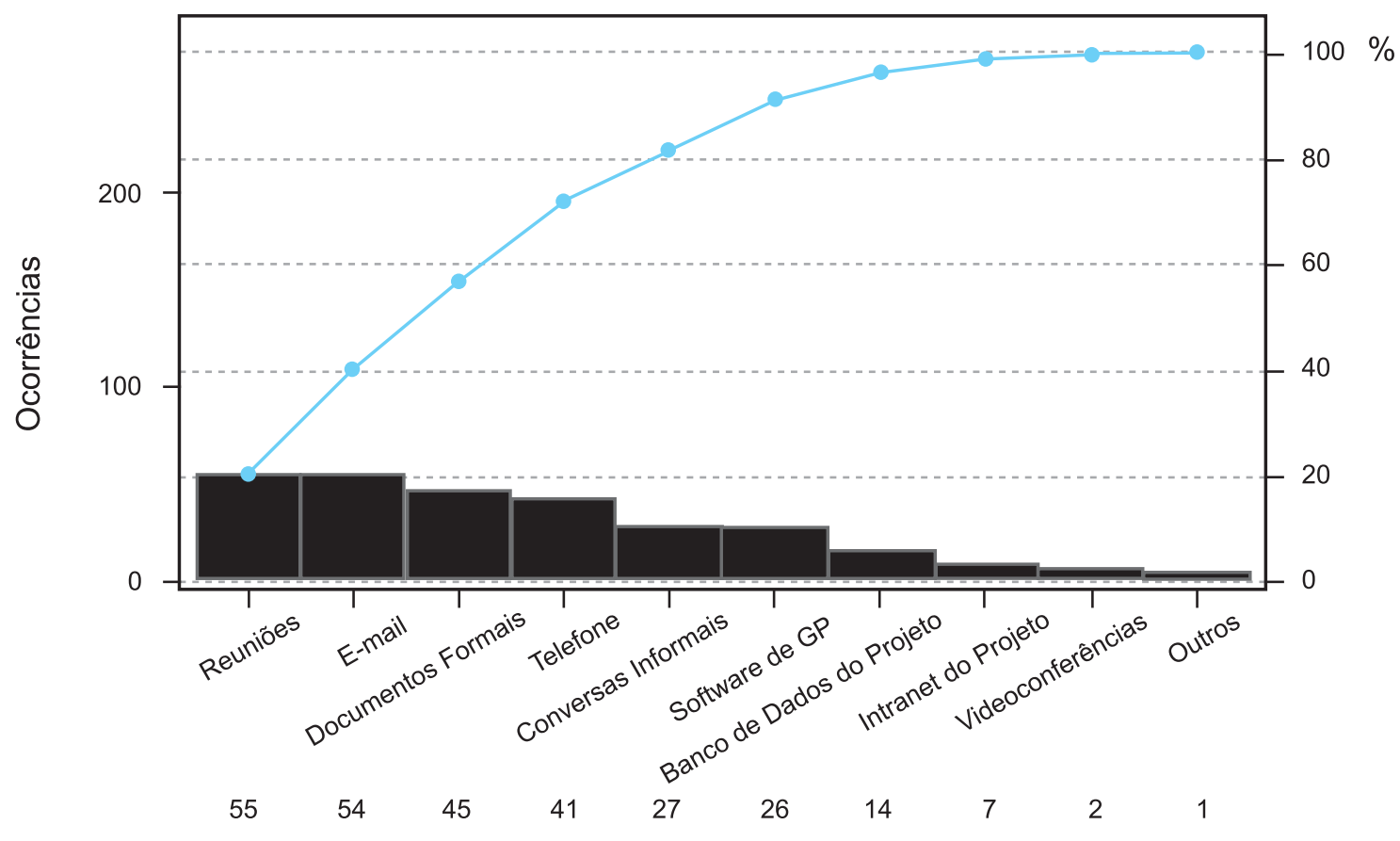

Tabela 6: Relatórios de desempenho.

\begin{tabular}{|l|c|c|c|c|c|c|}
\cline { 2 - 8 } \multicolumn{1}{c|}{} & \multicolumn{2}{c|}{ SISTEMAS } & \multicolumn{3}{c|}{ NEGÓcIOS } & \multicolumn{2}{c|}{ GERAL } \\
\hline Sim & 8 & $24 \%$ & 5 & $21 \%$ & 13 & $23 \%$ \\
\hline Praticamente Sim & 8 & $24 \%$ & 6 & $25 \%$ & 14 & $25 \%$ \\
\hline Praticamente Não & 11 & $33 \%$ & 10 & $42 \%$ & 21 & $37 \%$ \\
\hline Não & 5 & $15 \%$ & 3 & $13 \%$ & 8 & $14 \%$ \\
\hline Não sei & 1 & $3 \%$ & 0 & $0 \%$ & 1 & $2 \%$ \\
\hline
\end{tabular}

Tabela 7: Como são feitas as discussões de acompanhamento dos projetos.

\begin{tabular}{|c|c|c|c|c|c|c|}
\hline \multirow[b]{2}{*}{ Reuniões em № Suficiente p/ análise de desempenho } & \multicolumn{2}{|c|}{ SISTEMAS } & \multicolumn{2}{|c|}{ NEGÓGIOS } & \multicolumn{2}{|c|}{ GERAL } \\
\hline & 9 & $18 \%$ & 11 & $28 \%$ & 20 & $22 \%$ \\
\hline Não havia reuniões p/ análise de desempenho & 7 & $14 \%$ & 5 & $13 \%$ & 12 & $13 \%$ \\
\hline Reuniões esporádicas e não suficientes & 18 & $37 \%$ & 9 & $23 \%$ & 27 & $30 \%$ \\
\hline Era prática comum a discussão sobre planejado x realizado & 6 & $12 \%$ & 5 & $13 \%$ & 11 & $12 \%$ \\
\hline \multirow[t]{2}{*}{ Os resultados das análises eram documentados } & 9 & $18 \%$ & 10 & $25 \%$ & 19 & $21 \%$ \\
\hline & 49 & $100 \%$ & 40 & $100 \%$ & 89 & $100 \%$ \\
\hline
\end{tabular}


lado, 11 dos profissionais de negócio apontaram para a resposta reuniões em número suficiente para análise de desempenho, enquanto somente 9 profissionais de sistemas fizeram a mesma opção.

Uma questão adicional tratava do controle das lições aprendidas nos projetos concluídos, com cinco níveis de resposta possíveis, conforme Tabela 8 , que também dispunha de um espaço para comentários livres.

$\mathrm{Na}$ Tabela 8 observa-se que para a maioria dos entrevistados $(75 \%$ geral $)$, o controle das lições aprendidas no encerramento dos projetos não é uma prática freqüente na organização estudada (43\% praticamente não e 32\% não).

$\mathrm{Na}$ área livre para comentários, as formas citadas pelos participantes para registro de lições aprendidas foram: o Relatório de Avaliação do Projeto (citado por três entrevistados), diário de bordo, apresentações enviadas aos par- ticipantes, base de dados com informações do projeto, ata de reunião de encerramento, todas com uma citação cada. Dois entrevistados criticaram este processo da empresa estudada com os seguintes comentários: "lições são individuais e não corporativas" e "são poucos os gerentes de projetos que se preocupam com lições aprendidas e as distribuem a todos os integrantes do projeto". Finalmente destacase o comentário de um dos entrevistados, que ressaltou a importância deste controle com o seguinte comentário: " $a s$ discussões sobre as lições aprendidas são importantes a fim de não cometer as mesmas falhas em projetos futuros ou no próprio projeto em andamento".

\section{Barreiras à comunicação}

O bloco final do instrumento de pesquisa apresentava duas perguntas. A primeira pergunta era fechada sobre as

Tabela 8: Lições aprendidas.

\begin{tabular}{|c|c|c|c|c|c|c|}
\hline \multirow[b]{2}{*}{ Sim } & \multicolumn{2}{|c|}{ SISTEMAS } & \multicolumn{2}{|c|}{ NEGÓCIOS } & \multicolumn{2}{|c|}{ GERAL } \\
\hline & 3 & $9 \%$ & 0 & ०\% & 3 & $5 \%$ \\
\hline Praticamente Sim & 7 & 21\% & 4 & $17 \%$ & 11 & $20 \%$ \\
\hline Praticamente Não & 13 & $39 \%$ & 11 & $48 \%$ & 24 & $43 \%$ \\
\hline Não & 10 & $30 \%$ & 8 & $35 \%$ & 18 & $32 \%$ \\
\hline Não sei & 0 & ०\% & 0 & $0 \%$ & 0 & ०\% \\
\hline & 33 & $100 \%$ & 23 & $100 \%$ & 56 & $100 \%$ \\
\hline
\end{tabular}

Tabela 9: Principais barreiras à comunicação.

\begin{tabular}{|c|c|c|c|c|c|c|}
\hline PRINCIPAIS BARREIRAS & \multicolumn{2}{|c|}{ SISTEMAS } & \multicolumn{2}{|c|}{ NEGÓCIOS } & \multicolumn{2}{|c|}{ GERAL } \\
\hline Falta de confiança entre integrantes & 2 & $2 \%$ & 6 & $7 \%$ & 8 & $4 \%$ \\
\hline Resistência em compartilhar informações entre os integrantes & 13 & $11 \%$ & 8 & $10 \%$ & 21 & $11 \%$ \\
\hline Ambiente do Projeto & 9 & $8 \%$ & 5 & $6 \%$ & 14 & $7 \%$ \\
\hline Diferença de linguagem entre cliente e integrantes & 18 & $16 \%$ & 9 & $11 \%$ & 27 & $14 \%$ \\
\hline Diferença de linguagem entre sistemas e negócios & 23 & $20 \%$ & 14 & $17 \%$ & 37 & $19 \%$ \\
\hline Diferenças de percepção & 21 & $18 \%$ & 15 & $19 \%$ & 36 & $18 \%$ \\
\hline Não existência de um plano de comunicação do projeto & 21 & $18 \%$ & 15 & $19 \%$ & 36 & $18 \%$ \\
\hline Não existência de local para conversar sobre o projeto & 7 & $6 \%$ & 9 & $11 \%$ & 16 & $8 \%$ \\
\hline Clareza na especificação e objetivos do projeto & 1 & $1 \%$ & 0 & $0 \%$ & 1 & $1 \%$ \\
\hline \multirow[t]{2}{*}{ Prazo curto dificultando ênfase na comunicação } & 1 & $1 \%$ & 0 & $0 \%$ & 1 & $1 \%$ \\
\hline & 116 & $100 \%$ & 81 & $100 \%$ & 197 & $100 \%$ \\
\hline
\end{tabular}


barreiras à comunicação durante a condução dos projetos, organizada em 10 níveis, na qual o entrevistado podia opinar por mais de uma resposta, conforme a Tabela 9. A segunda pergunta era aberta e buscava identificar os principais facilitadores no processo de comunicação.

As três barreiras que foram apontadas pelo maior número de respondentes, tanto no cômputo geral como nas áreas, foram: diferença de linguagem entre sistemas e negócios (19\% geral), diferenças de percepção (18\% geral), não existência de um plano de comunicação do projeto (18\% geral). Portanto, $19 \%$ dos respondentes acreditam que existe barreira de comunicação entre os profissionais de sistemas e de negócios. A título de ilustração citam-se dois comentários oriundos de áreas diferentes sobre as dificuldades de comunicação entre as áreas:

"É difícil explicar para os donos do processo, que são da área de negócios, o que é possível fazer com a tecnologia disponível, pois eles às vezes pedem coisas impossíveis" (relatado por um analista de sistemas).

"Nós da área de negócio estamos conectados às demandas do cliente, mas o pessoal de sistemas coloca dificuldades intransponíveis e se esconde atrás de um linguajar técnico, o que dificulta uma negociação e a solução do problema" (relatado por um gerente de negócios).

$\mathrm{Na}$ área livre para comentários, foram ainda citados pelos entrevistados os seguintes fatores facilitadores:

- Elaboração de um plano formal de comunicações

- Condução de reuniões de acompanhamento, porém previamente agendadas entre os participantes.

- Elaboração de atas de reuniões com distribuição a todos os interessados no projeto.

- Utilização, com bom senso, de e-mail para a divulgação do andamento do projeto.

- Formalização de todos os documentos.

- Comprometimento dos integrantes do projeto e

- Afinidade entre os integrantes.

\section{CONCLUSÕES}

Em qualquer organização sempre haverá divergências de opiniões, mal entendidos e até mesmo certa "rivalidade" entre as pessoas quando tentam defender suas idéias. Entretanto, quando se trata de projetos, é imprescindível que todos os integrantes e clientes tenham os mesmos objetivos.

Observa-se pelos resultados da pesquisa de campo que se por um lado há uma exaltação à importância da comunicação (ver Tabela 1), observa-se que os processos envolvidos na área de comunicação em projetos são pouco trabalhados na empresa estudada. O plano formal de comunicações é realizado apenas em uma pequena porcentagem dos projetos de TI da empresa estudada, bem como nem a elaboração de relatórios de desempenho (ver Tabela 6), nem o controle das lições aprendidas (ver Tabela 8) no encerramento dos projetos são práticas freqüente na organização estudada.

\section{xistem diferenças significativas de percepção da importância da comunicação em projetos entre os profissionais de negócios e de sistemas.}

É possível perceber também que existem divergências significativas na percepção da importância das comunicação em projetos, para os profissionais de sistemas e de negócios, quando comparada às demais áreas de conhecimento em GP (ver Tabela 2).

Duas das três barreiras de comunicação mais citadas pelos respondentes apontam para as diferenças de linguagem entre sistemas e negócios e as diferenças de percepção. A terceira barreira mais citada foi a não existência de um plano de comunicação do projeto.

Os resultados desta pesquisa apontam para a necessidade de estudos futuros para identificar as causas das diferenças de percepção que podem ser oriundas de divergências culturais, restrições tecnológicas, estrutura organizacional entre outros fatores que podem impactar no peso atribuído à importância da comunicação em projetos.

É importante também investigar se existem também diferenças significativas para as demais áreas de conhecimento em GP, em especial a área de suprimento que apresentou percepção divergente na amostra estudada.

Finalmente, destaca-se que este estudo focou os profissionais envolvidos em projetos de TI e para sua extensão para outros tipos de projeto novas pesquisas devem ser feitas. 


\section{- Referências}

ARANTES, Nélio. Sistemas de gestão empresarial. São Paulo: Atlas, 1998.

BELOUT, A.; GAUVREAU, C. Factors influencing project success: the impact of human resource management. International Journal of Project Management, v. 22,2004 , p. $1-11$

CARVALHO, M. M; LAURINDO, F. J. B.; PESSÔA, M. S. P. Information Technology Project Management to achieve efficiency in Brazilian Companies. In: KAMEL, S. (Org.). Managing Globally with Information Technology. Hershey, p. 260271, 2003.

CARVALHO, M. M.; RABECHINI, JR. R. Construindo Competências para Gerenciar Projetos: teoria e casos. São Paulo: Editora Atlas, 2005.

Gestão de Projetos na Prática: casos brasileiros. São Paulo: Editora Atlas, 2006.

DINSMORE, P. C. Winning Business with Enterprise Project Management. New York: Amacom, 1998.

FERREIRA, A.B.H. Dicionário Aurélio básico da língua portuguesa. Rio de Janeiro: Nova Fronteira, 1988.

FERREIRA, J. M. C. (org). Psicossociologia das organizações. Portugal, Lisboa: McGraw-Hill, 1996.
FOX, S. Effective communication: stone age to e-comm. Proceedings of the Project Management Institute Annual Seminars \& Symposium, USA, Nov. 2001.

GRANOT, M. A Pratical Approach to Project Control. Proceedings of the 28th Annual Project Management Institute 1997 Seminars \& Symposium, p. 1012-1015.

HUMPHREY, W. S. Managing the software process. Reading, Addison-Wesley (SE series in software engineering), 1989.

KIM, D. H. Loops de criação de paradigmas: como as percepções moldam a realidade.

KIRSC, J. L.; et al. Controlling Information Systems Development Projects: The View from the Client. Management Science, v. 48 , n. 4, p. 444-498, April 2002.

WARDMAN, K. T. (Org.) Criando organizações que aprendem. Futura, 1996.

MOSCOVICI, F. Desenvolvimento interpessoal. Rio de Janeiro: LTC, 1985.

MUCHIELLI, R. A condução de reuniões. São Paulo: Martins Fontes, 1993.

PINTO, J. K; SLEVIN, D. P. Critical factors in successful project implementation. In FINCH,P. Applying the project implementation profile to an information systems project. Project Management Journal, v. 34 n. 3 ; p. $32,1987$.
PINTO, J. K.; PRESCOTT, J. E. Variations in critical success factors over the stages in the project life cycle. Journal of Management, v. 14, n. 1, p. 5-18, 1988.

PINTO, JR. J. K.; MANTEL S. J. The causes of project failure. IEEE Transactions on Engineering Management, v. 37, n. 2, p. 69-76, 1990.

PINTO J. K.; SLEVIN D. P. Project success: definitions and measurement techniques. Project Management Journal, v. 19, n. 3, p. 67-73, 1988 .

PMI, Project Management Institute. A Guide to the Project Management Body of Knowledge (PMBoK). 3rd edition. Project Management Institute Inc., 2004.

PMI, Project Management Institute. Organizational Project Management Maturity Model (OPM3). Maryland: Project Management Institute Inc, 2003.

PMI, Project Management Institute. A Guide to the Project Management Body of Knowledge (PMBoK). 2nd edition. Project Management Institute Inc., 2000.

OBIKUNLE, O. F. Project management communication: a multicultural dimension. Proceedings of the Project Management Institute Annual Seminars \& Symposium, USA, Nov. 2001.
PASOLD, C. L. Comunicação nas relações humanas organizacionais. Florianópolis: Estudantil, 1987.

PENTEADO, J. R. W. A técnica da comunicação humana. São Paulo: Pioneira, 1980

RABECHINI JR., R.; CARVALHO, M. M.; LAURINDO, F. J. B. Fatores críticos para implementação de gerenciamento por projetos: o caso de uma organização de pesquisa. Revista Produção. São Paulo, v. 12 n. $2,2002$.

ROCKART, J. F. Chief executives define their own data needs. Havard Business Review, v. 57, n. 2, p. 81-92, Mar/Apr. 1979.

ROSS, R. A escada de inferência. In SENGE, P. et al. A quinta disciplina: caderno de campo: estratégias e ferramentas para construir uma organização que aprende. Rio de Janeiro: Qualitymark, 1999.

RUUSKA, I.; VARTIAINEN. Critical project competence: a case study. Journal of Workplace Learning, v. 15 , n. $7 / 8$, p. $307-312,2003$.

YIN, R. K. Case Study Research: Design and Methods. Newbury Park: Rev. ed. Sage Publications, 1991.

\section{- Agradecimentos}

Os autores agradecem ao CNPq pelo apoio financeiro e aos revisores anônimos pelas sugestões dadas.

\section{- Sobre os autores}

\section{Marly Monteiro de Carvalho}

Profa. Dra. do Depto de Eng. Produção - Escola Politécnica da USP

End.: Av. Prof. Almeida Prado, 128, Tr. 2 Biênio, 2o andar - 05508-900 - São Paulo - SP - Brasil

Tel.: (11) 3091-5363 Fax: (11) 3091-5399

E-mail: marlymc@usp.br

\section{Daniela Mirandola}

Mestranda do Depto. de Eng. Naval - Escola Politécnica da USP

End.: Av. Prof. Almeida Prado, 128, Tr. 2 Biênio, 2o andar - 05508-900 - São Paulo - SP - Brasil

Tel.: (11) 3091-5363 Fax: (11) 3091-5399

E-mail: daniela.mirandola@globo.com 